\title{
Electrochemical Performances of a Thin Film Type SOFC on a Porous Microtubular Support
}

\author{
T. Yamaguchi ${ }^{\mathrm{a}, \mathrm{b}}$ and N. Sammes ${ }^{\mathrm{a}}$ \\ ${ }^{a}$ Department of Metallurgical and Materials Engineering, Colorado School of Mines, \\ Golden, Colorado 80401, USA \\ b Advanced Manufacturing Research Institute, National Institute of Advanced Industrial \\ Science and Technology, Nagoya, Aichi 463-8560, JAPAN
}

This report summarizes electrochemical performances of a thin film type SOFC prepared on a porous microtubular support. The sample was prepared via the co-sintering of YSZ electrolyte and $\mathrm{NiO}-\mathrm{YSZ}$ anode bilayers on a porous microtubular YSZ support, and then an LSCF-GDC cathode layer was also prepared on the electrolyte film. Evaluations were conducted using impedance analyzer and potentio/galvanostat under a humidified hydrogen flow. Film thickness of the anode layer was controlled by the composition of the anode coating suspension and the coating conditions (coating number and coating speed etc.). Impedance analyses showed that with increasing operation temperature, semicircle at higher frequency region became small, while semi-circle at lower frequency region weakly depended on the temperature. Electrode activation energy was calculated to be approximately 80 $\mathrm{kJ} / \mathrm{mol}$ using Arrhenius plot on the semi-circle at higher frequency region.

\section{Introduction}

Solid oxide fuel cells (SOFCs) have received a great deal of attention lately, due to in part to their high energy conversion efficiency and environmental compatibility. Intermediate temperature operation of SOFCs can realize a widening the range of applicable materials (for example, metallic interconnects and glass sealants), and a decrease in material degradation and start-up time, which can result in cost reduction and elongation of the SOFC stack lifetime [1-3]. The use of alternative high performance electrolytes and electrodes materials means that the SOFC operation temperature can be reduced $[4,5]$.

In addition, miniaturization of the cell size and integration of multiple miniaturized cells is also considered to be one of the most effective approaches to increase the volumetric power density [6]. Recently, the technologies have been intensively investigated to reduce operation temperatures, reduce size, and hasten start-up and shutdown operations [7-9]. Among various proposed cell designs, a micro tubular SOFC design exhibits many desirable characteristics, such as increasing the net electrode area per unit volume and the durability to thermal stress caused by rapid start-up operation [10-12]. In the case of tubular SOFCs, down-sizing the cell size enables an increase in the number of cells that can be accumulated in a certain volume, which leads to an increase in the net electrode area per volume. Thus, it is possible to increase the volumetric power 
density of SOFC modules at lower SOFC operation temperatures by gaining a large electrode area per volume, even though the power density of the cell tends to decrease at the lower temperature range.

Very recently, various researchers reported the excellent electrochemical performances and durability of heat-cycles for microtubular SOFC designs. Most of the cells are supported by a porous anode tube. Therefore the anode tubular support works as a current collector and gas diffusion layer as well as support medium of SOFC. Thus, the aim of this study is to investigate the availability of thickness and microstructure of anode for the performances of microtubular SOFCs by focusing on the anode activation layer. This report summarizes electrochemical performances of an anode activation layer prepared on a porous microtubular support.

\section{Experimental}

The samples were prepared via the co-sintering of $8 \mathrm{~mol} \% \mathrm{Y}_{2} \mathrm{O}_{3}$-doped $\mathrm{ZrO}_{2}$ (YSZ) electrolyte and 60wt\% NiO-40wt\% YSZ anode bilayers on a porous microtubular YSZ support, and then an application of a commercial $50 w t \%\left(\mathrm{La}_{0.6} \mathrm{Sr}_{0.4}\right)\left(\mathrm{Co}_{0.2} \mathrm{Fe}_{0.8}\right) \mathrm{O}_{3-\mathrm{x}}$ (LSCF)-50wt\% $\left(\mathrm{Ce}_{0.9} \mathrm{Gd}_{0.1}\right) \mathrm{O}_{1.95}$ (GDC) cathode ink on the electrolyte film. Initially, YSZ tubular support was extruded using a mixture of YSZ powder, organic binder and water. The tubular support has a diameter approximately $1.6 \mathrm{~mm}$ with a fuel gas channel of approximately $1.3 \mathrm{~mm}$ in diameter. The NiO-YSZ anode, YSZ electrolyte and LSCFGDC cathode layers were prepared by wet-coating and heating at each temperature, described below. The NiO-YSZ anode and YSZ electrolyte coating slurries were prepared by ball-milling the ceramic powder, ethanol and toluene mixture solvent, poly vinyl butyral binder, organic dispersant surfactant, and plasticizer (triethylene glycol di2-ethylhexanoate) for $72 \mathrm{~h}$. The green extruded YSZ tube was dipped into the NiO-YSZ anode and YSZ electrolyte slurries, followed by co-sintering at $1300{ }^{\circ} \mathrm{C}$ for $2 \mathrm{~h}$ in air. The NiO-YSZ/YSZ-coated tube was applied with the LSCF-GDC cathode ink, and then

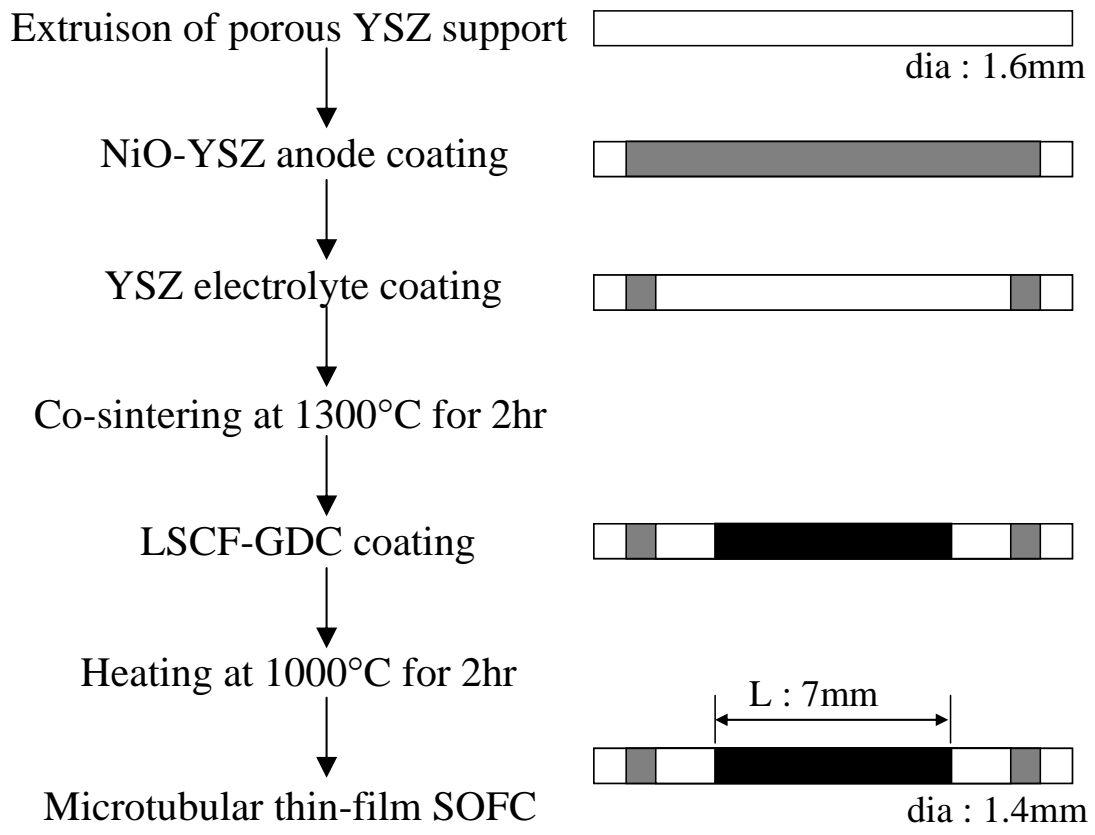

Fig.1 Fabrication procedure of a thin film type SOFC supported on porous microtubular YSZ support 
the tube was heated at $1000{ }^{\circ} \mathrm{C}$ for $2 \mathrm{~h}$ in air. The completed tubular cell has a diameter of approximately $1.4 \mathrm{~mm}$ and a cathode length of approximately $7 \mathrm{~mm}$, that is, the effective electrode area is approximately $0.3 \mathrm{~cm}^{2}$. Figure 1 shows the experimental set-up for testing of a thin film type SOFC supported on a porous microtubular YSZ support.

The performance of the cell was measured from 650 to $750{ }^{\circ} \mathrm{C}$ using a Chroma 6310 series for current-voltage characterization, and a Gamry 600 for impedance analyses under humidified $\mathrm{H}_{2}\left(3 \% \mathrm{H}_{2} \mathrm{O}\right)$ gas flow at a flow rate of $25 \mathrm{~cm}^{3} / \mathrm{min}$ and open air. Ag wire was used for current collection from the anode and cathode sides, and the wires on both sides were fixed using Ag paste (903-B; ESL ElectroScience). Current collection from the anode was conducted by winding a Ag wire around the edge of the anode support. Figure 2 shows the cell setup in this report. The impedance measurements were conducted in a frequency range from $0.1 \mathrm{~Hz}$ to $100 \mathrm{kHz}$ with a signal amplitude of $5 \mathrm{mV}$ under open-circuit condition.

Ag wires for Cathode current collection

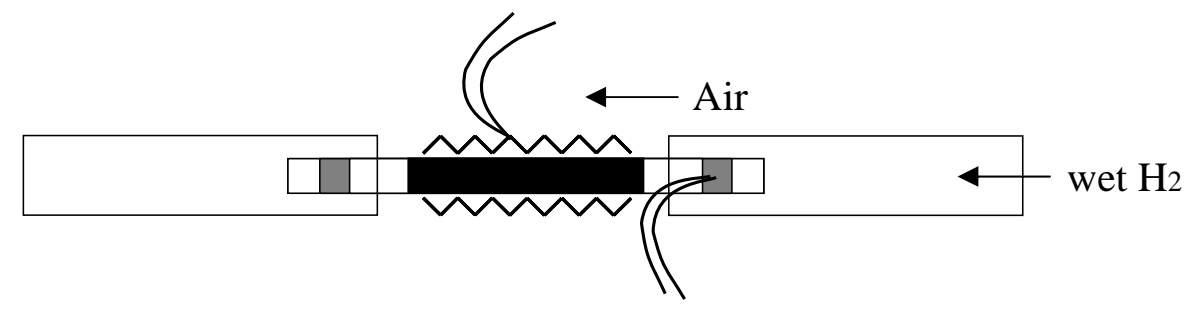

Ag wires for Anode current collection

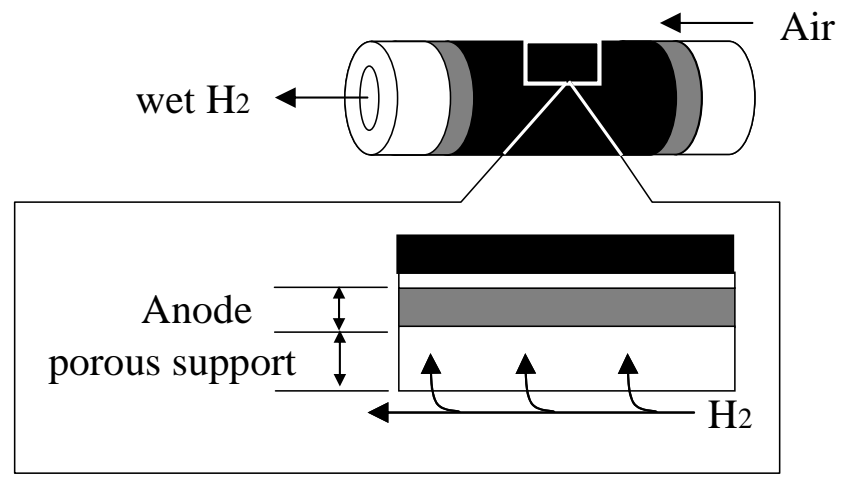

Fig.2 Cell set-up for electrochemical measurements used in this study

\section{Results and Discussion}

Figure 3 shows the voltage and power density of the micro SOFC as a function of current density from 650 to $750{ }^{\circ} \mathrm{C}$. The open circuit voltages (OCVs ) were above 1.03 V. A commercial ceramic bond was used as the gas sealant for the single-cell measurements. In view of gas leakage through the ceramic bond layer with partial gas tightness, it is considered that the YSZ electrolyte was adequately densified. The maximum power densities were 34, 50 and $69 \mathrm{~mW} / \mathrm{cm}^{2}$ at 650,700 and $750{ }^{\circ} \mathrm{C}$, respectively.

Figure 4 shows the impedance spectra of the micro SOFC from 650 to $750{ }^{\circ} \mathrm{C}$. The ohmic resistances were $0.461,0.426$ and $0.396 \Omega \cdot \mathrm{cm}^{2}$ at 650,700 and $750{ }^{\circ} \mathrm{C}$, respectively. Compared to the ohmic resistance of $10 \mu \mathrm{m}$ thick YSZ [5], the one in this 
study weakly depended on the temperature (Fig. 5), which indicates that the in-plane ohmic resistance for the thin film anode layer is dominant in the total ohmic resistance.

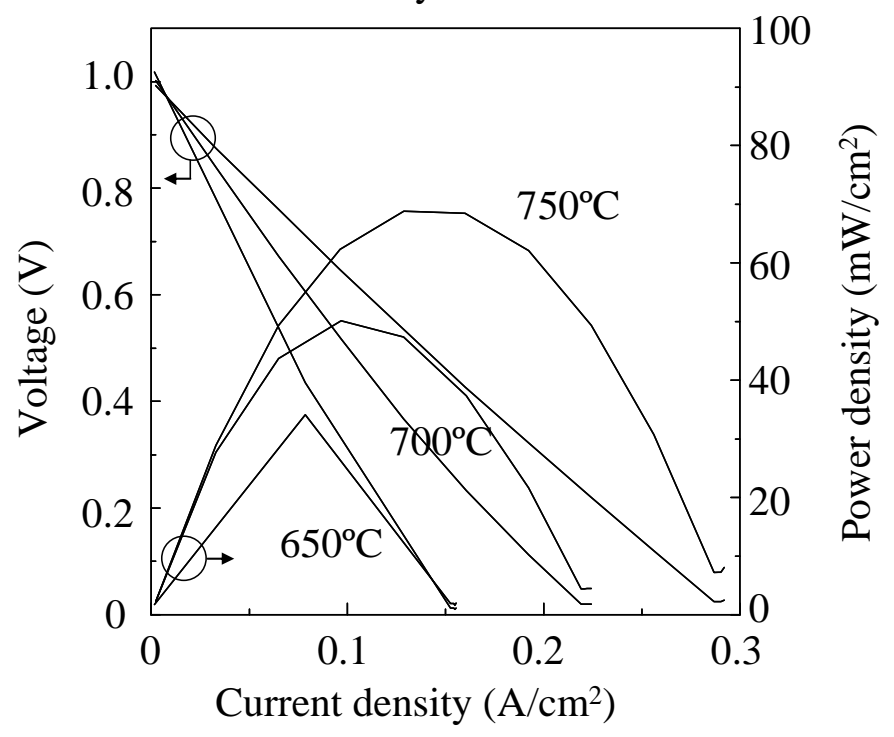

Fig.3 Power densities of the thin film type SOFC supported on porous microtubular YSZ support as a function of current density from 650 to $750{ }^{\circ} \mathrm{C}$

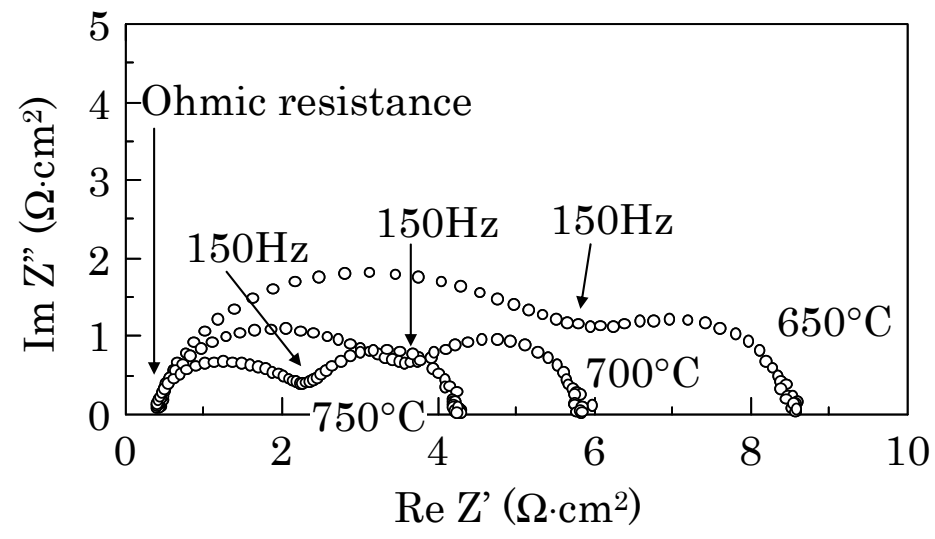

Fig.4 Impedance spectra of the thin film type SOFC supported on porous microtubular YSZ support as a function of current density from 650 to $750{ }^{\circ} \mathrm{C}$

On the other hand, the electrode polarization separated two different regions: (1) from ohmic to $150 \mathrm{~Hz}$ with strong temperature dependence and (2) from 150 to $0.1 \mathrm{~Hz}$ with weak temperature dependence. With increasing the operation temperature, the semi-circle at higher frequency region shrunk in size, in contrast the semi-circle at lower frequency region became clearly distinguishable. Figure 6(a) summarizes the temperature dependence of the electrode polarizations separately plotted at two frequency regions (1) from ohmic to $150 \mathrm{~Hz}$ and (2) from 150 to $0.1 \mathrm{~Hz}$. The electrode polarization at higher frequency region followed Arrhenius plot with an activation energy of $80 \mathrm{~kJ} / \mathrm{mol}$ as can be seen in Fig. 6(b), which shows that the semi-circle from ohmic to $150 \mathrm{~Hz}$ in Fig. 4 is mainly attributed electrode activation energy. On the other hand, the electrode polarization from 150 to $0.1 \mathrm{~Hz}$ with weak temperature dependence is considered to result from the gas diffusion polarization for the porous microtubular support. 
Currently we are trying to improve the cell performance by optimizing the support porosity (gas diffusivity), anode thickness (ohmic resistance), and anode activity (amount of three phase boundary) [9].

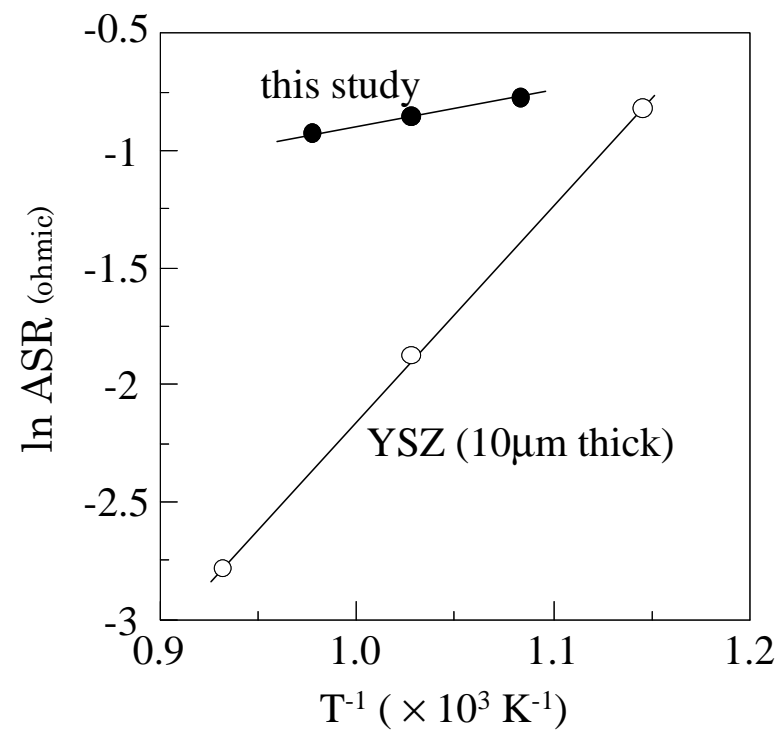

Fig.5 Arrhenius plot of ohmic resistance of the thin film type SOFC supported on porous microtubular YSZ support, compared with $10 \mu \mathrm{m}$ thick YSZ
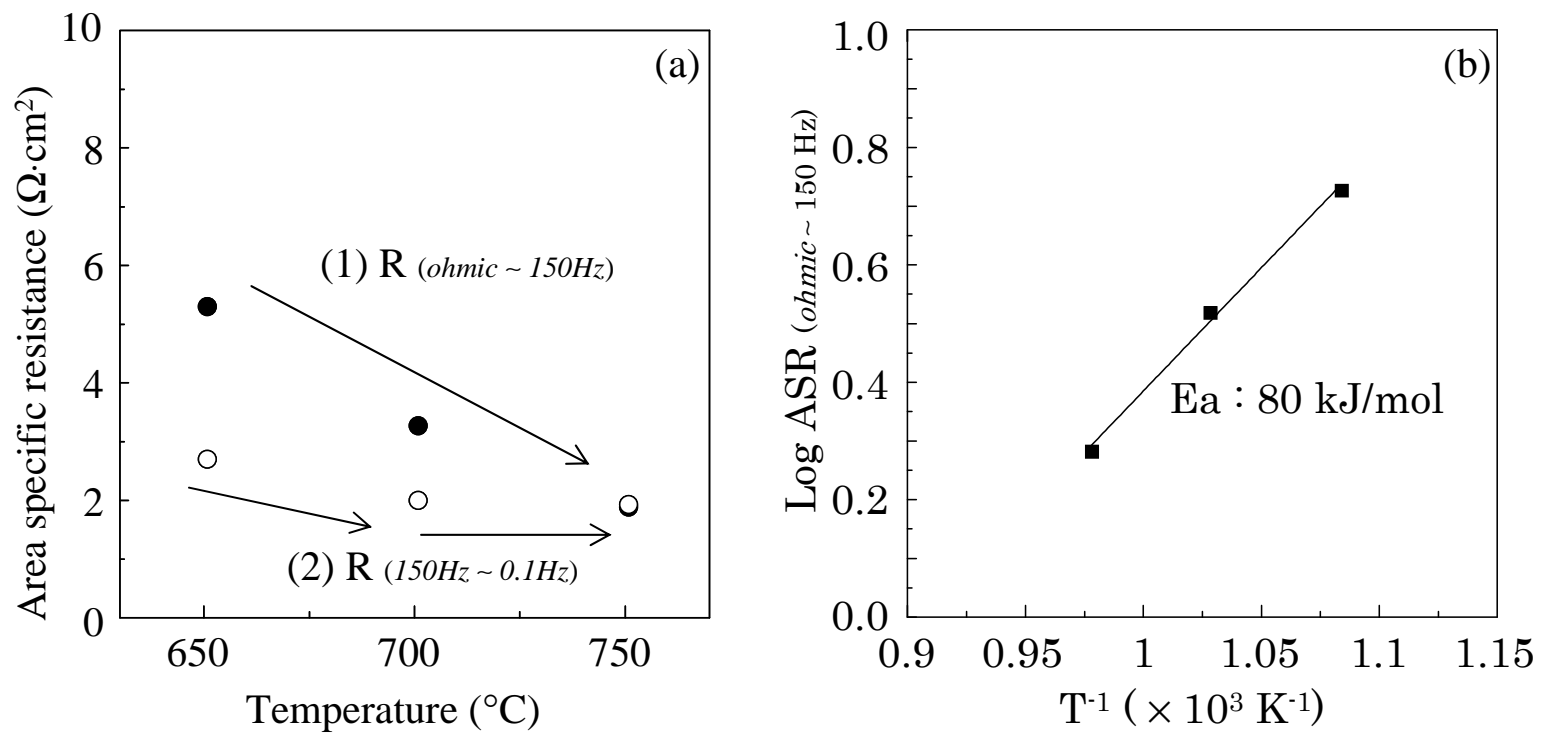

Fig.6 (a) Temperature dependence of electrode polarizations, and (b) Arrhenius plot of the electrode polarization from ohmic to $150 \mathrm{~Hz}$ region

\section{Acknowledgements}

This study was supported by the Japan Society for the Promotion of Science (JSPS); Excellent Young Researcher Overseas Visit Program. I am grateful to Dr. Neal Sullivian in Colorado Fuel Cell Center for supplying the YSZ powder. 


\section{References}

1. M. Dokiya, Solid State Ionics, 152-153, 383 (2002).

2. T. Hibino, A. Hashimoto, M. Yano, M. Suzuki, S. Yoshida and M. Sano, J. Electrochem. Soc., 149, A133 (2002).

3. T. Ishihara, J. Tabuchi, S. Ishikawa, J. Yan, M. Enoki and H. Matsumoto, Solid State Ionics, 177, 1949 (2006).

4. B. C. H. Steele and A. Heinzel, Nature, 414, 345 (2001).

5. J. W. Fergus, J. Power Sources, 162, 30 (2006).

6. N. M. Sammes, Y. Du and R. Bove, J. Power Sources, 145, 428 (2005).

7. Y. Funahashi, T. Shimamori, T. Suzuki, Y. Fujishiro and M. Awano, ECS Transactions, 7, 643 (2007).

8. T. Yamaguchi, S. Shimizu, T. Suzuki, Y. Fujishiro and M. Awano, Electrochem. Commun., 10, 1381 (2008).

9. T. Suzuki, Z. Hasan, Y. Funahashi, T. Yamaguchi, Y. Fujishiro and M. Awano, Science, 325, 852 (2009).

10. I. P. Kilbride, J. Power Sources, 61, 167 (1996).

11. K. Kendall and M. Palin, J. Power Sources, 71, 268 (1998).

12. K. Yashiro, N. Yamada, T. Kawada, J. Hong, A. Kaimai, Y. Nigara and J. Mizusaki, Electrochemistry, 70, 958 (2002). 